IRA-International Journal of Education \& Multidisciplinary Studies

ISSN 2455-2526; Vol.14, Issue 03 (March, 2019)

Pg. no. 54-66.

Institute of Research Advances

Institute of

Research

http://research-advances.org/index.php/IJEMS

\title{
Understanding Developmental Characteristics of a Child in Christian Faith among Sunday- School Children in Kenya
}

\author{
Alice W. Mambo \\ Lecturer and Head of the Department of Education, Africa International University, P. O. Box. \\ 24686, 00502, Karen, Nairobi, Kenya.
}

Type of Work: Peer Reviewed

DOl: http://dx.doi.org/10.21013/jems.v14.n3.p3

How to cite this paper:

Mambo, A.W (2019). Understanding Developmental Characteristics of a Child in Christian Faith among Sunday-School Children in Kenya. IRA International Journal of Education and Multidisciplinary Studies (ISSN 2455-2526), 14(3), 54-66.doi: http://dx.doi.org/10.21013/jems.v14.n3.p3

(C) Institute of Research Advances.

This work is licensed under a Creative Commons Attribution-Non Commercial 4.0 International License subject to a proper citation to the publication source of the work.

Disclaimer: The scholarly papers as reviewed and published by the Institute of Research Advances (IRA) are the views and opinions of their respective authors and are not the views or opinions of the IRA. The IRA disclaims of any harm or loss caused due to the published content to any party.

Institute of Research Advances is an institutional publisher member of Publishers International Linking Association Inc. (PILA-CrossRef), USA. The institute is an institutional signatory to the Budapest Open Access Initiative, Hungary advocating the open access of scientific and scholarly knowledge. The Institute is a registered content provider under Open Access Initiative Protocol for Metadata Harvesting (OAI-PMH).

The journal is indexed \& included in WorldCat Discovery Service (USA), CrossRef Metadata Search (USA), WorldCat (USA), OCLC (USA), Open J-Gate (India), EZB (Germany) Scilit (Switzerland), Airiti (China), Bielefeld Academic Search Engine (BASE) of Bielefeld University, Germany, PKP Index of Simon Fraser University, Canada. 


\begin{abstract}
This paper extensively presents the theme of Christian education with a focus on the Sunday school children in Kenya. The author reviews the developmental stage characteristics of the Sunday school children of the Anglican Church to express the aspect of child Christian education in the contemporary society. While Parents are entrusted with the primary responsibility of nurturing, shaping, training and equipping their children to be God-honoring, obedient, and productive members in society; this responsibility in the modern society has been passed on to secular surrogates who do the educating in their place. It is nonetheless still the key responsibility of parents that their children receive rightful Christian education.The study is limited to children between ages two to eleven years in the church Sunday school in a Kenyan context. More so, the guidelines in this study are limited to the Sunday school for the Christian education of children in the Anglican Church of Kenya with which the author is more conversant.
\end{abstract}

Keywords: Anglican Church, Children education, Developmental characteristics, Sunday school.

\title{
Introduction
}

The concern about children's ministry by the church of Jesus Christ is to enable the children to experience the reality of God. Thus, in carrying out its mandate to nurture the children, the church must focus on its purpose, which mainly consists of helping children to identify God's self - disclosure where it meets their own experience, and then the church should nurture and encourage response. To be effective, Christian education must be grounded solidly in Christian revelation and must minister to persons in the light of their individual maturity, physical and social environment, previous experience and training, ability to learn, and above all, basic needs.

Wyckoff [1] defines Christian education as:

...a lifelong process by which persons are led to a commitment to Jesus Christ through helping them to understand and accept the Christian faith and its implications for time and eternity; and to an increased understanding and more effective expression to Christian faith in relation to God and all human relationship [p. 21].

Pazmino [2] highlighted the importance of Christian education in the present generation by stating that:

Christian education is a vital ministry which deserves our best efforts and can be a source of joy and renewal in the life of the Christian church. Without effective education, the faith is not faithfully passed on to the rising generations and Christians are not obedient to their educational commission (Matthew 28:18-20). It is also a lifelong, ongoing dialogical process that seeks to discern God's truth and to foster through loving relationships the expression of God's reign [p. 276].

The most pressing problem facing children's ministry in the Kenyan churches today is the fact that teachers concentrate more on telling it. The "telling" easily diverts children from the work of engaging the Bible directly to the degree of their ability. A child must believe the gospel in order to be saved, and he cannot believe in it unless he hears it. Modern research that has been conducted to enhance educational approaches to better reach students with relevant learning skills has brought about a change in the theory of educational practices. Christian educators need to understand and implement best practices discovered through research and also believe that modern educational research does not change the foundational biblical principles which must always serve as the bedrock of all learning and truth [3]. Christian education teachers must not only prepare the standard lesson plan for Bible lessons for the children but must also possess and refine a biblical understanding of each lesson they prepare so as to create a biblical framework for all that goes on in the Sunday school.

It is sad but true that a child may attend Sunday school and church faithfully for years and not hear the simple gospel. Hence, very few children experience the gospel. Most of them think that one can be saved by being good, or by being baptized or by joining the church [4]. Our purpose in advocating the gospel to children is to show them that they need a Savior and that the Lord Jesus is the very Savior they need. And then we must encourage the child to receive that Savior. 
It's important to note that Christian education has properly emphasized the significance of childhood. Matthew, Markand Luke all tell the story of parents coming to interrupt Jesus with the hope of receiving from Him a blessing for their children (Matthew 19:13-15; Mark 10:13-16; Luke 18:15-17). The disciples, who apparently thought children were not important enough to take Jesus' time, tried to turn the parents and their little ones away. To their surprise, Jesus did have time for the children. In his response to the disciples, we find two significant insights about the Kingdom of God. Jesus commanded the disciples to let the children come to Him because the Kingdom of God belongs to them. Jesus continued with an even more amazing statement: anyone who wants to enter the Kingdom of God must receive it as a little child. Children, not just adults, belong in God's Kingdom. Furthermore, they are not marginal members of the Kingdom, just tagging along with their parents, waiting to grow up and become real members. No, children are models in the Kingdom of God, showing adults how to enter [5]. White [6] states that, "Because we are privileged to be alongside children (those who Jesus has placed in the middle of our lives) we are uniquely situated to receive little children as signs and models of the Kingdom of God, and to communicate something of this revelation to others" [ p. 60]. Our Lord's rebuke of the disciples, His examples of setting children in their midst, and His comparison of the simplicity and openness of a child to receiving the kingdom of God set an agenda for the Christian education of children.

Christ's teaching is clear that the Christian's duty to the child is absolutely binding. To receive a child is to receive none other than Jesus Himself. For it was as a lowly Babe that God sent into our world, His own son, the Savior who was the great final revelation of Himself. Hence, unless a person becomes like a child he cannot enter God's spiritual Kingdom (Mathew 18:3) [5, pp. 14-15].

Helping children acquire faith in themselves, in others and in the ultimate goodness of life is the central task of religious educators everywhere in society today. Therefore, Christian education of children is imperative because children are gifts from God and they are open to Him. Children deserve to be helped to moral and spiritual maturity. Thus, early consistent saturation in a warm, Christian nurturing environment helps them respond personally to Christ's call to salvation. Christian faith is never more than one generation from extinction. "Hence there is a need to carefully plan the learning exposures of our children to unfold them the mighty acts of God in such a way as to help them arrive at the same sound faith we possess" [7, p. 68].

\section{Methodology}

The primary method used in this study is library and experiential research in educational theory, utilizing class lectures, reference books and journals, as well as analysis of its applicability to the Kenyan cultural context and integration of the writer's personal experience as a Sunday school superintendent in a local church, as a Bible college tutor and as a secondary school teacher in the area of Christian Religious Education and Ethics.

\section{Discussion}

\section{Developmental Characteristics of Children}

The church must always in its ministry to children, know both the faith that it seeks to communicate and the children to whom it ministers. A basic understanding of their characteristics and needs is essential to help them most effectively in their development including determining the content and method to be used in Christian education.

Bush [8] indicates that "in human development, there is no more critical period in childhood than the decade encompassed by the 4/14 window (ages 4 to 14). It is a profoundly formative period when perspectives are shaped either positively or negatively and when a view of one's own significance (or lack thereof) is formulated. The needs and potential of this age group should inspire a purposeful response by those charged today with transforming tomorrow's world. It is a call as indicated in Malachi 4:6to turn the hearts of fathers to their children and the hearts of children to their fathers" [p. 1].

Children come in all sizes, shapes and behaviours. In many respects, children are alike and yet different because they are individuals in their own right. They are not miniature adults, and we should not expect adult behaviour from them. Although different authorities stress a different number of developmental stages, child development refers to a child's ability to learn and master skills called milestones as she gets older. A milestone in child development is a skill that a child learns at a specific stage of development. The acquisition of milestones occurs in a certain sequence 
in the areas of physical, emotional, and mental abilities. A child graduates from one stage of development to the next after reaching certain milestones. For instance, a child learns to crawl before walking and running. The stages of child development begin at birth [9]. Because development is influenced by both heredity and environment, the developmental characteristics of one child will often vary greatly from another's. Choun [10] notes that "standards for age group characteristics and needs allow teachers to make informed choices when designing schedules, furnishing rooms, and selecting teaching methods. Instead of treating children like miniature adults, teachers can tailor their lessons to meet the specific needs of each level of development" [p. 127]. Childhood is as distinct a period in life as the youth or adult years. Childhood extends from birth through eleven years of age. Lopes [11], divides them into several periods:

$\begin{array}{lc}\text { Early infancy } & 0-2 \text { years } \\ \text { Late infancy } & 2-3 \text { years } \\ \text { Early childhood } & 4-5 \text { years } \\ \text { Middle childhood } & 6-8 \text { years } \\ \text { Late childhood } & 9-11 \text { years [p. 42] }\end{array}$

In this paper, the term 'children' refers to human beings during their early to later childhood years (Age two to eleven). This is the period of primary school education. Erikson views development as an evolutionary process based upon a universally experienced sequence of biological, psychological, and social events and involves an auto therapeutic process to heal the scars created by natural and accidental crises inherent to development. Development in itself "consists of a series of childhood which call for a variety of sub-environments, depending on the environment experienced during previous stages" [12, p. 304]. The developmental characteristics of children include physical, psychosocia1, social, cognitive, moral and faith characteristics.

\section{Physical Characteristics}

The study of physical development theory is necessary because, as we seek to learn the characteristics of children, we will understand that the child's physical growth and physical needs have a great influence on his spiritual development as well as on his cognition and behaviour.

During the first six years of life, the child's organs and physiology grow in size and maturity as they develop different physical capacities which help give them a basis for learning. Growth in height is fairly rapid in early childhood, slows down for a while in middle childhood, then takes a spurt during adolescence. During this period, infants are developing the motor skill of prehension the ability to grasp and hold an object, and the skill of locomotion the ability to move about and get from one place to another. The increasing efficiency of motor activity is influenced by the rapid development of the brain. The child's brain grows faster during the first two years of life than it will at any other time $[13,14]$.

When a child reaches the age of six to nine he progresses relatively slowly in physical development. His muscular development is uneven, and the small muscles of his hands are not fully developed, so he lacks fine muscular coordination, but his lungs and heart grow rapidly. His baby teeth are replaced by his six-year molars. At this time the focus for the child is on physical and social activities.

From age ten to twelve, the child has slow steady growth; small muscles develop in boys and girls increase in weight around the thighs and waist while at the same time their eye-hand coordination improves. Between eleven and thirteen years the child reaches a period of rapid growth in height, weight, muscular development, and sex organs.

To a large extent, the factors influencing growth are genetically determined [15] But certain basic traits and growth sequences are typical of all humans. The general course of development is similar for both sexes, although girls tend to mature more rapidly and earlier than boys. Hamachek[16] has stated that:

By the onset of puberty, the average girl of eleven years is around 58 inches tall and the average boy of the same age is about 57.5 inches. By the time the average boy reaches twelve years of age he will have attained approximately 84 per cent of his mature adult height. Girls, on the other hand, reach approximately 92.6 per cent of their mature adult height at the same age [p. 72]. 
Motor development accounts for significant physical growth during the preschool years. Because of this, development activity is a chief characteristic of a preschooler. He likes to move and learns through activity when it is planned and guided. The most dramatic physical transition occurs in his late childhood years when pre-pubertal changes begin. Children are very active and can concentrate on a task for a significant amount of time if they are actively involved in it. They involve their entire bodies in whatever they do.

The physical growth and development of a child certainly affect his self-concept and attitudes [17, p. 49]. The importance of physical health and development in learning cannot be overemphasized. In this respect Linskie[18] suggests an important factor in maintaining good physical health, "a certain amount of personal freedom is another requisite for physical well-being" [p. 5]. Therefore, the physical well-being of a child is important because a child needs to make use of his whole body in order to learn effectively.

\section{Psychosocial Characteristics}

The psychosocial concept, in general, represents an individual seeking to find an orientation for himself or herself in relation to the society in which the individual lives. Out of the conflict or confrontation of the individual with the social forces, there emerges a sense of self [19].

Socialization is seen as a reciprocal process; the child influences adultbehaviours as certainly as adults influence a child's behaviours. A Child's pattern of behaviour ranges from shy to bold, passive to active, cuddly to distant, lethargic to alert, serious to carefree. However, in the psychosocial view, physical maturation has personal and social repercussions. Maturation brings a new skill that opens up new possibilities for the child but also increases society's demands on him, such as pressures to talk instead of cry when he wants something. Hence, there is a "fit" between the child and his culture [20], p. 160]. Erikson speaks of a"cogwheeling" of life cycles meaning that each child is a life cycle in a community of life cycles [12, p. 121].

Psychosocial development proceeds according to the epigenetic principle and genesis. This principle originates from fetal development. Erikson [21] indicates that:

Somewhat generalized, this principle states that anything that grows has a ground plan, and that out of this ground plan the parts arise, each part having its time of special ascendency until all parts have arisen to form a functioning whole. At birth, the baby leaves the chemical exchange of the womb for the social exchange system of his society, where his gradually increasing capacities meet the opportunities and limitations of his culture [p. 92].

In his psychosocial model, which he divides into eight stages from childhood to adulthood, Erikson considers individuals in relation to their parents within the context of a family and in relation to the broader socia1-cultural heritage in which families live. He sees each human being as having the potential to produce "good" or "bad" actions. Each of the eight stages, according to Erikson, has its own conflict and crisis that represent an opportunity for growth and development. Atkinson [22] indicates that "Erickson believes that human beings face eight major crises, or conflicts, during the course of their lives. He described the eight stages of growth as developing in increasing complexity, emerging directly from the previous stage, and building on earlier stages in a cumulative manner. His eight stages are bipolar in nature and each stage can emerge in either a healthy or unhealthy direction, depending on whether influences are enriching or abusive. These bipolar crises must be confronted and negotiated before an individual can successfully resolve subsequent phases. In addition, each stage contributes a quality or virtue to the developing personality"[p. 254]. The first four critical periods that Erikson discusses when certain lifelong ego concerns reach their climax are herein briefly considered.

The first stage which he refers to as "Basic Trust versus Basic Mistrust" deals with a child from birth to eighteen months old. The first task of an infant is to develop what Erikson calls "the cornerstone of a healthy personality," a basic sense of trust in him or herself and the surrounding environment [21, p. 45].

He goes on to define basic trust as "an essential trustfulness of others as well as a fundamental sense of one's own trustworthiness" [21, p. 96] and a sense that there is some correspondence between the child's needs and his world [23, p. 15]. 
The first year of a child's life is a time when he is completely and utterly dependent on the outside world to attend to his most basic needs. If his assorted needs are not met with a reasonably predictable consistency, he may gradually develop a mistrust of the world around him. The child's capacity of being able to depend on other people has its roots during this stage. Hence, it is important to note that, if children's needs are met by warm, loving parents, they will learn to trust; if met by cold, unsupportive and unreliable parents, they will develop personalities characterized by feelings of fear, insecurity, untrustworthiness and suspicion. Therefore, if a basic sense of trust is not developed during the first year, it becomes increasingly difficult to establish in later years. The virtue of hope is associated with this stage. Infants must learn to trust others to care for their basic needs. The parents or primary caregiver are the key social agent.

The second stage deals with "Autonomy versus Shame and Doubt" and covers roughly from eighteen months to three years. This is the time that a child discovers that his behaviour is his own. He begins to assert his newly discovered sense of autonomy by demanding that "I can do it myself. Don't help me." The child begins to emerge from total dependence on their parents. They begin to do things on their own, such as feeding themselves and crawling or walking. Erikson reasons that a child experiences conflicting pulls: one to assert himself and the other to deny himself the right and capacity to make this assertion. To live in a healthy way during this stage means that the child expands his limits aggressively, acts on his own terms, and insist on his own boundaries.

Adults can encourage a healthy sense of autonomy in a child during this phase through a wise balance of firmness and permissiveness. Letting a young child do whatever he pleases is not a healthy way to help him find his strengths because they have nothing against which to measure themselves. The responsibility for establishing limits rests with parents and teachers. A child is pliable; if he knows and fully understands the range of his limits, their growth and learning will be healthy for this will enable them to have the ability to carry out certain age-appropriate tasks alone. The emerging strength in this stage is the will to do what is expected.

In contrast, limits that are too restrictive and adults who are too protecting can interfere with a child's natural inclination to want to test them and to try to explore different ways. Without such exploration, a child will be plagued with self-doubts because he is uncertain about what he can or cannot do and may end up having a sense of shame at their failures or doubting of their capabilities. The negative component of this stage is shame which Erikson [24] describes as "an emotion that supposes that one is completely exposed and conscious of being looked at in a word self-conscious" [p. 253]. It is during this stage that a child develops the beginnings of a sense of autonomy which does not stop here. Developing autonomy is necessary for the emergence of the initiative, which brings us to the next stage.

The third stage, "Initiative versus Guilt," covers ages three through six years. Having discovered that he can do things for himself, the child becomes curious about how much he can do and when and where. Acquiring a sense of initiative involves thrusting out into a wider world of childhood and assuming new interests and activities. Energy levels are high, curiosity is profound, and explorations are vigorous. If they are encouraged and supported in their endeavours to discover and learn new things, they will likely develop self-confidence. Erikson thinks that the very act of moving out more aggressively into the social world is the beginning of a process that helps a child see that he can have a certain amount of power and that life has a purpose for him.

Also during this stage, a child begins to develop a conscience, a sense of right and wrong. If this tendency to feel guilty is overtaxed by moralistic or punitive parents and teachers, a child can easily develop a feeling of "badness" that could seriously inhibit healthy urges to test himself in an expanding social world. Moreover, if they are discouraged from or punished for their self-initiated activities, guilt and fear of trying new things will be produced. This is a time when a child engages in the complicated process of finding out who he is and what he can do, and he can only do this if he has a certain amount of freedom to do so without feeling guilty about it.

The fourth and last stage in childhood development deals with "Industry versus Inferiority," which includes ages six to twelve years. Children in this stage expand their social environment from home and family to the neighbourhood and school. Here the "industrial age" begins when a child becomes ready to apply himself to given skills and tasks, which go far beyond the mere playful expression of his organ modes or the pleasure in the function of his limbs, thus developing industry [24, p. 259]. Here the theme is "I am what I learn" [12]p. 82]. Successfully learning to relate to peers, performing academic tasks, and playing by the rules leads to competence and industry. 
During this phase of growth, a child can learn to have a healthy view of himself through his increased competence in doing things. In learning to accept instruction and to win recognition and approval by producing 'things' that open the way for the capacity of work enjoyment in later years. The danger in this period is the development of a sense of inadequacy and inferiority in a child who does not receive recognition for his efforts. Thus, children's inability to function in their social environment may result in a sense of inferiority throughout life.

From Erikson's theory, we learn that a child's 'self' goes through different phases as he progresses through the first four stages of psychosocial development. These phases are a developmental framework to help us understand that, even though growth is a continuous process, certain crises occur at different points in the life cycle, each of which must be successfully resolved before the child can effectively meet the subsequent psychosocial stage.

Teachers, therefore, should seek to provide opportunities for learning activities in the class, giving pupils a chance to express their feelings when children are under crises, for crises are good opportunities for learning, and working to develop an accepting rather than rejecting attitude. The rules should be firmly established and ample opportunity provided for each pupil to be successful at learning new Christian truths which should be applied in daily life.

\section{Social Characteristics}

Social development theory is concerned with the way a child is able to relate to his environment and whether he is developing satisfactory ways of living with people. The child starts life with a demanding, self-centred approach and slowly learns to consider other persons for their own sake and take interest in the rights of his associates.

Social development involves learning the value, knowledge and skills that enable children to relate to others effectively and to contribute in positive ways to family, school and the community. This kind of learning is passed on to children directly by those who care for and teach them as well as indirectly through social relationships within the family or with friends, and through children's participation in the culture around them. Through their relationships with others and their growing awareness of social values and expectations, children build a sense of who they are and of the social roles available to them. As children develop socially, they both respond to the influences around them and play an active part in shaping their relationships.

While parents and caregivers are clearly the first and most important influences on children's social development, there are many other influential aspects of the social environment. People and settings that are involved with the child include family, school, teachers, peers, extended family, and any community, church cultural or religious groups a child may be part of. Children are also shaped by the broader social circumstances that impact on their families and communities, such as access to social and health services, parents' employment and income, or their ability to balance work and family time. In particular, children's sense of social connection is often influenced by community attitudes and by cultural values, including those they encounter in the media. Through their relationships and connections with others, children build a sense of who they are and where they fit in the social world. Coming to an understanding about self and others is, therefore, a central goal of children's social development ["Social Development," 2012].

"Play behaviour provides a fascinating view of social development. Before eighteen months, children react to each other as objects, not as playmates. Between eighteen and thirty-six months, true social interests emerge" [25, p. 102]. From 3 years on, peers become increasingly important. Play progresses from associative play to a cooperative play at four. Such progress assumes adequate social interaction with peers as Maier[26] has stated:

Play provides an opportunity for the child to explore by trial and error, the make-up of his immediate universe. The play opens the door for exploring, relatively unhampered, physical properties and causality. Play occurs without promise or threat of much reinforcement by extrinsic rewards, and remains in the child's territory, essentially free from the intrusion of an elder. At the same time, a child can incorporate his parents' and teachers' behaviour at his leisure and he can express his joy or frustration and anger through acceptable play activities [p. $131]$.

During the primary years, a child's peers are extremely important. A child relates to peers on equal status and the quality of those relationships determines his ego strength and behaviour. "All the boys are doing it," is logical 
excuse to justify the behavior of almost any primary age boy. Parents and teachers, therefore, must not abdicate their leadership and authority before the child is ready for excessive independence.

\section{Cognitive Characteristics}

Not only do dramatic changes occur in the physical, psychosocial and social aspects in children, but they also emerge in the cognitive aspect. Barlow [19] indicates that cognitive development deals with mental processes of imagination, memory, perception and reason. It is also concerned with how a person takes random stimuli from the environment and then processes this material into meaningful information.

Understanding a child's intellectual development is necessary for teaching, working with or just loving him. No theorist has contributed more to our understanding of children's thinking than Jean Piaget (1896-1980), a Swiss scholar who began to study intellectual development during the 1920s. Piaget undertook several experiments among children of various ages and concluded that the process of thinking develops as a child grows. Regardless of the culture in which he lives or the learning experiences he has, a child goes through the same stages in the same sequence. A child cannot reach higher stages of thinking without having gone through the lower stages. Each stage is controlled by a maturational unfolding. This means that a child can think only in a way characteristic of that particular stage in which he is at any particular time. A child's construction of reality depends upon the maturational stage he has reached.

Jean Piaget viewed intellectual growth as a process of adaptation (adjustment) to the world. This happens through Assimilation- Which is using an existing schema to deal with a new object or situation. Accommodation- This happens when the existing schema (knowledge) does not work and needs to be changed to deal with a new object or situation. Equilibration- This is the force, which moves development along. Piaget believed that cognitive development did not progress at a steady rate, but rather in leaps and bounds. Equilibrium occurs when a child's schemas can deal with most new information through assimilation. However, an unpleasant state of disequilibrium occurs when new information cannot be fitted into existing schemas (assimilation). Equilibration is the force which drives the learning process as we do not like to be frustrated and will seek to restore balance by mastering the new challenge (accommodation). Once the new information is acquired the process of assimilation with the new schema will continue until the next time we need to make an adjustment to it [27]. Piaget sees a child, not as a miniature adult, but a philosopher who perceives the world only as he has experienced it. The child is born into egocentrism. He sees himself as the center of the universe, with everything revolving around him and occurring solely for his pleasure. A child can understand only what he has experienced himself, and he expects adults to see things exactly as he does [28, p. 12].

Piaget's theory of cognitive development stresses four major periods through which humans pass in the course of intellectual maturation. The four major periods (or stages) include the sensorimotor stage (birth to age 2), the preoperational stage (ages 2 to 7), the concrete operational stage (ages 7 to 11), and the formal operational (ages 11 and beyond). These ages are only rough estimates and vary from culture to culture and individual to individual. These stages form what Piaget called an invariant developmental sequence that is, all children progress through the stages in exactly the order in which they are listed. There is no skipping of stages, because each successive stage builds on the previous stage and represents a more complex way of thinking, although some individuals may never attain the later stages [29]. The first three periods which cover the childhood years are briefly examined.

During the sensorimotor stage, which covers birth through two years, Piaget believed that infants are primarily occupied with processing sensory input, trying to co-ordinate motor behaviour in response to sensory stimuli. The child becomes aware of a spatial relationship through such motor activities as reaching and grasping. He develops concepts of time dimension having a before and after rather than only immediate experience and an awareness of causality of how one event leads to another. The child's understanding of the world involves only perceptions and objects he has. Towards the end of this stage; the ability to form primitive mental images develops as the infant acquires object permanence. Piaget further divides the sensorimotor periods into six sub-stages. These sub stages are however not dealt with in this paper. During the preoperational stage, which covers ages three through to seven years, the child is not yet able to think logically. With the acquisition of language, the child is able to represent the world through mental images and symbols, but here symbols depend on his own perception and his intuition. For example, many children will call any four-footed creature a cat or a dog, depending on what label they have assigned to four-footed creatures. The child in this stage is completely egocentric and curious. Since he knows the world only from his limited experience, he makes up explanations when he does not have one. Children believe that 
natural phenomena are man-made and that everything that has life isa way in which they create explanations for confusing experiences. During the last half of the preoperational stage, children begin to grasp logical concepts and become less egocentric in their thinking. Nevertheless, still their thinking is unsophisticated, and they have difficulty manipulating more than one idea or concept at a time [19].

The third stage is referred to as concrete operations and covers ages seven through to eleven years. It is during this stage that most children enter primary school. Piaget points out that their most important change is their newly acquired ability to use mental operations in making sense of their environment. Piaget defines operation as "the ability to manipulate concepts internally." During this stage, the child can manipulate two or more objects logically, but his thinking is still very closely tied to objects and events that are present or that he has previously experienced in a concrete manner. Hence, the child can think logically as long as he has something in front of him to which he can concretely relate.

The true goal of cognitive development should be to give each child ample opportunity and encouragement to achieve levels reasonable for his age and commensurate with his mind. This can be achieved by providing a proper Sunday school curriculum program that keeps children in contact with their feelings, encourages original ideas and problem solving, fosters the use of language and provides practice in certain reasoning and thinking skills.

Christian educators can benefit from an understanding of cognitive development in at least three ways. First, awareness of different characteristics of thought processes at each stage of development of children provides teachers with insights for creating age-appropriate learning experiences and choosing suitable teaching techniques. Second, Christian educators are reminded that religious teaching must take into account the intellectual abilities of learners at various stages of growth. The teacher must neither overestimate nor underestimate the cognitive ability of the student. Third, effective teachers actively engage children in the teaching/learning process [22].

\section{Moral Characteristics}

Morality has to do with the everyday life of persons, their words and behaviours.Morals always move from egocentric to socio-centric. As a result of socialization, a child learns acceptable and unacceptable behaviour, ethical and unethical conduct of his society. Through his interaction with siblings and peers, he may learn to practice rules democratically in the form of mutual give and take. Morals are important in faith development which is grounded in a broader aesthetic, a knowing which gives us eyes to see"what is going on," and "what God is doing, and enables us to see how to make our lives-and our acts-fitting' in relation to the larger action of which we are a part" [30, p. $65]$.

To understand the moral development of a child, we will examine the findings of Kohlberg's research on moral reasoning. Kohlberg is known for his cognitive theory of moral development, which drew on philosophical reflection and empirical psychological research. Influenced by Kant, Baldwin, Piaget, and Dewey, Kohlberg was concerned with questions such as "What is a virtue?" and "What is justice?" His theory of moral development was shaped around the universal moral principle of justice which he defined as the recognition of an individual's rights as well as the individual's acknowledgement of the rights of others. Expanding on Piaget's two-stage model of moral judgment development, Kohlberg in his theory identified three levels with six stages of development, each of which represents qualitatively distinct moral reasoning. The stages are invariant in sequence and no stages may be skipped. While the pace of development varies by individuals, development may cease at any stage [31]. In this paper, only the first two levels which deal with children between ages four to thirteen years are considered.

The first level is what Kohlberg calls "pre-conventional," because children do not yet respond, as members of the society. At this level, the child is responsive to cultural rules and labels of good and bad, right or wrong, but interprets these labels in terms of either the physical consequences of the action, in form of punishment, reward, exchange of favor in terms of the physical powers of those who make the rules and labels. This level is divided into stage one and stage two which cover the childhood years.

During the first stage, which is referred to as "punishment and obedience

orientation" or "you do what you are told" [32, p. 17], the physical consequences of an action determine its goodness or badness regardless of the human meaning or value of these consequences. Good behaviour is associated with avoiding punishment. 
During stage two, which is referred to as the "instrumental relativist orientation," or "let's make a deal," Crain [33], p.108] notes that good behaviour is associated with satisfying one's own desires and needs without considering the needs of others. Although children show some awareness of fairness, it is usually in the sense of what they get out of the exchange, they are still concerned with personal needs but view human relations in terms of the market place hence the saying "if you scratch my back, I'll scratch yours" [34, p. 491].

A child in stage two is still said to reason at the pre-conventional level because he speaks as an isolated individual rather than as a member of the society. He sees individuals exchanging favours, but there is still no identification with the values of the family or community.

Older children may be entering the conventional level, which comprises stages three and four. Such persons are developing a feeling of loyalty to the group, family, school, peer group or community and a sense of identity within the group. In stage three which Kohlberg calls the "good boy-nice girl orientation," the child of about ten years acts in ways that will win approval. Children here are less egocentric and are developing the ability for wider relationships. Their selfhood is not threatened by being part of a social group.

In stage four which is referred to as theLaw and Order Orientation," right behaviour consists of keeping the law, respecting authority and helping to maintain the social order. This is a commendable way to act because children are required to keep the law [35], p. 81).

Moral training is part of religious training. Within the Christian community, Kohlberg is regarded as an optimist. According to Dykstra [36], one of the critical problems with Kohlberg's theory stems from the fact that he does not take sin seriously. He contends that repentance, prayer and service are ways to improve moral development.

We grow morally as we repent, pray and serve in the increasingly complex ways that human development requires and in the variety of contexts that range from relationships, with loved ones to strangers. We cannot do this alone however; we need to be in a community that supports us, guides us, and undertakes these disciplines with us. For Christians that community is the church [p. 113]

When teaching children, teachers should expect a variety of responses and recognize that younger children respond to moral dilemmas differently than older children. Stress concrete actions rather than abstract principles when teaching younger children. Teachers should increase awareness of moral issues by discussing real hypothetical moral dilemmas in class and using experiences in the classroom as opportunities to heighten moral awareness. The most effective strategy in developing moral reasoning skills is to discuss alternative responses to one stage above the child's level of reasoning. Presenting stage three reasoning to a stage two reasoner will be more effective than presenting stage two or stage four alternatives. A child can grow in morality through the Christian education offered both at home and in the church.

\section{Faith Characteristics}

As mentioned previously at the beginning of this paper, helping children acquire faith in themselves, in others, and in the ultimate goodness of life is the task of religious educators everywhere. Faith is a first-hand experience. It must be experienced before it can be shared. No child grows up faithless. Faith is learned in the context of relationships, and all children have relationships of some sort. The term "faith" here is not limited to creeds or religions. Rather, as a generic or universal feature of the human struggle for identity, community, and meaning, it is an exceedingly broad and complex reality [37, p. 180].

Faith development theory and research have focused on a generic understanding of faith that sees it as a foundational to social relations, to personal identity, and to the making of personal and cultural meanings [38, 39]. Fowler and Dell [40] indicate that:

Like many dimensions of our lives, faith seems to have a broadly recognizable pattern of development. This unfolding pattern can be characterized in terms of developing emotional, cognitive, and moral interpretations and responses. Our ways of imagining and committing in faith correlate significantly with our ways of knowing and valuing more generally. We are asking you to think of faith in a more inclusive sense that Christian, Buddhist, Islamic, or Judaic faith. Faith, 
in the sense used here, even extends beyond religious faith. Understood in a more inclusive sense, faith may be characterized as an integral, centering process, underlying the formation of the beliefs, values, and meanings [p. 36]

James Fowler defines faith as "an orientation of the total person, giving purposes and goals to one's hopes and strivings, thoughts and actions." He explains that faith is relational40, p. 14]. Moreover, according to Dykstra and Parks [42], faith begins in a relationship. Faith implies trust in another, reliance upon another, a counting upon or dependence upon another. This faith is started from infancy when a baby trusts his or her parents [p. 16]. The other side of faith as trust is faith as an attachment, as commitment and as loyalty.

Faith is "a person's or a community's way-of-being-in-relation to an ultimate environment" [43, p. 24]. In this understanding, faith is tri-polar or triadic and covenantal. In Christian Jewish terms, the ultimate environment is expressed with the term "Kingdom of God" and is the center of value and power.

It is important to note here that the understanding of faith as relational cannot be separated from faith as an active knowing and being in which the self makes a bid for a relationship from a center of value and power. Knowing means acting upon and "composing" the known. Knowing occurs when an active knower interacts with an active world of persons and objects, meeting its unshaped or unorganized stimuli with the ordering, organizing power of the knower's mind [42, p. 19]. Being includes loving, caring, valuing, and also awe, dread, and fear. In this understanding, faith is active.

To explain this, Fowler says that faith is not a noun, but a verb, "faithing." The understanding of faith as a verb is clear in the Greek word pistuo and the Latin credo which are both verbs [41, p. 16].

The understanding of faith as an active or dynamic phenomenon of knowing leads to the understanding of faith as an imagination because we cannot see the ultimate environment. We know it through our perceptive capacities or images. Faith development, therefore, has to do with constructing these images.

Having understood the concept of faith, I would now like us to turn our attention to Fowler's theory which he divides into six developmental stages, starting from toddlerhood to adulthood. Each stage represents a "structure" of faith, a way in which faith is thought of and a means by which faith meaning is made, a form or worldview. The stages are invariant in sequence, and each successive stage integrates previous stages while expanding one's faith capacities. Development is not automatic and may be arrested at any stage. For example, an individual may reach chronological adulthood while remaining in the faith stages of childhood or adolescence [31]. Since our paper covers the childhood years, we will only deal with his first and second stages, without discussing his opinion on the pre-stage.

Fowler considers infancy as a pre-stage which he calls "undifferentiated faith," because to him, "the seeds of trust, courage, hope and love which infants receive are fused in an undifferentiated way and content with sensed threats of abandonment, inconsistencies and deprivations in an infants' environment [41, p. 121]. Here, Fowler refers to Erickson's first stage and concludes that basic trust and the mutual relationship between a child and the ones providing love and care become important foundations for the child's faith. Any deficiency in this stage is due to the failure of mutuality, and it may lead a child into excessive narcissism. Fowler [41] further notes that "the transition to stage one begins with the convergence of thought and language, opening up the use of symbols in speech and ritual play" ([p. 121].

Fowler [41] refers to stage one as "intuitive-protective faith which covers children from ages two to seven years old[p. 133]. This is a time of unrestrained fantasy and imagination when long-lasting images and feelings, both positive and negative are formed. Fact and fantasy are not yet differentiated. As a consequence, symbols are taken literally and God is thought of in anthropomorphic, magical terms. For example, many children at this stage view God as an old man with a beard who can do everything. There is an awakening of memory and self-consciousness, and the capacity to take the role of another is beginning, but only in a very rudimentary form. The dangers in this stage arise from the possible "possession" of the child's imagination by unrestrained images of terror and destructiveness. The main factor precipitating transition to the next stage is the emergence of concrete operational thinking. 
The "mythic-literal faith" of stage two, according to Fowler, includes ages eight to twelve years [p. 135]. It is affiliative faith stage in which a person comes more consciously to join and belong to his faith community. The way of making meaning becomes more linear and narrative rather than episodic as in stage one. The child's ultimate environment is conceptualized in those stories and myths which are taken literally. Reasoning and thought beyond institution take place at this time, but thinking is still in concrete sensory terms, with little abstraction possible. The child begins to differentiate the natural from the supernatural, but God continues to be understood largely in anthropomorphic terms [44, p. 70]. Concerning this, Fowler [41] points out that:

Religious faith must name and face that deep-going tendency in us to make ourselves, and the extensions of ourselves central in the world. From sin, self-absorption and all the life strategies and structures arising from them, religious faith provides liberation and redemption, linking us to communities of shared memory and shared hope with which we join in symbolizing our human condition and in enacting the visions that can animate and give new life [p. 293]

So far we have examined the various developmental characteristics attributed to children at different stages. As the teacher studies the personalities of his pupils, he stands in a better position to pattern his teaching in a way that will appeal to their interests and at the same time will relate Scriptural truths to their lives, thus helping them develop Christ-like attitudes and habits.

In spite of the rapidly changing environment around them, children themselves have not changed. Children continue to grow physically, mentally, socially, emotionally, and spiritually in predictable patterns and stages. We know that each child we teach is a unique creation of God, with special characteristics and personality traits. To be an effective teacher, it is important to personalize learning and build a relationship with each child. As Christian educators, we have a biblical mandate to teach and care for the children because they are human beings who are created in the image of God, because they need the love of Jesus Christ and because they play an important role in the future of the world.

\section{Conclusion}

Children's workers in the church are involved in a divine program of helping to shape young lives. This makes it imperative that those leaders understand how personalities of children develop. Scripture makes it very evident that our Lord is concerned about each person as an individual, unique from any other individual. Likewise, each teacher must know his pupils individually, their personalities and characteristics if, he is to tailor his teaching to their personal needs.

Teachers are significant role models. A child will imitate, or become like their teachers. As parents, it is important to help ensure that the children have suitable role models. The Apostle Paul encourages us to "follow me as I am also of Christ." 1 Corinthians 11:1. The importance of the Christian education of children should not be underestimated and in order to teach and prepare adequate educational programs for children, there is a need to understand fully their developmental characteristics. The childhood period is foundational during which the basic personality structure and habits of life and character are fairly well developed. The patterns of life become increasingly complex and more difficult to change as a person enters adolescence and adulthood. So during this early stage, children need to be nurtured and helped in a proper way so as to develop towards maturity in every aspect of life. By understanding the various developmental characteristics of children, Christian educators are in a better position to develop a curriculum design for children's education which will include; objectives, scope, context, teachinglearning process, methods, leadership development and resource materials.

\section{References}

[1]. Wyckoff, C. D. (1961).Theory and design of Christian education curriculum.Philadelphia, PA: Westminster Press.

[2]. Pazmino, R. W. (2008). Foundational issues in Christian education: An introduction in evangelical perspective $\left(3^{\mathrm{rd}}\right.$ ed.). Grand Rapids, MI: Baker.

[3]. Pethtel, G. J. (2011). Christian education in the 21st century: Renewing a transformational vision. Available at https://books.google.com.

[4]. Eager, G. B.(1979).How to succeed in winning children to Christ.Minneapolis, MN: Viking Press Inc.

[5]. Stonehouse, C.,\& May, S. (2010). Listening to children on the Spiritual Journey: Guidance for those who teach and nurture. Grand Rapids, MI: Baker. 
[6]. White, K. J. (2011, March).Children as signs of the Kingdom of God: A challenge to us all Matthew 18:1-14. A compendium of papers presented at the Now \& Next Theological Conference on Children, Nairobi, Kenya.

[7]. Chaplin, D. P. (1961). Children and Religion (Rev. ed.). New York: Scribner's Sons.

[8]. Bush, L. (2009). The 4/14 window: Raising up a new generation to transform the world. Colorado Springs, CO: Compassion International.

[9]. Oguejiofo, N. (2015). Stages of child development.

Available at https://www.livestrong.com/article/107915-six-stages-child-development/.

[10]. Choun, R. J. (2001). Childhood Christian education.In M. Anthony (Ed.), Evangelical dictionary of Christian education (pp. 125-127). Grand Rapids, MI: Baker.

[11]. Lopes, V. (1988).The child: A simple child study manual. Langenbruck, Switzerland: CEF Press.

[12]. Erikson, E.H. (1959). Identity and the life cycle. New York: W. W. Norton \& Company.

[13]. Cunningham, S. (2001) Child development: Introduction. In M. Anthony (Ed.), Evangelical dictionary of Christian education (pp. 121-124). Grand Rapids, MI: Baker.

[14]. Aukerman, D. R. (2008). A history of the Sunday school in the Church of God.Anderson, IN Anderson University School of Theology.

[15]. Gagne, N. E. (1970). The conditions of learning (2nded.). New York: Holt, Rinehart \& Winston.

[16]. Hamachek, D. E. (1977). Human dynamics in psychology and education: Selected readings (3rd ed.). Boston, MA: Allyn and Bacon.

[17]. Zuck, R. B.,\&Clark, R. E.(1975).Childhood education in the Church.Chicago, IL: Moody Press.

[18]. Linskie, R. (1977). The learning process: Theory and practice. New York: Litton Educational Publishing, Inc.

[19]. Barlow, D. (1986). Educational psychology: The teaching-learning process. Chicago: Moody Press.

[20]. Miller, P. H.(1983).Theories of developmental psychology.San Francisco, CA: W. H. Freeman and Company.

[21]. Erikson, E. H. (1968). Identity youth and crisis. New York: W. W. Norton \& Company.

[22]. Atkinson, H. (2001). Erikson, Erick Homburger. In M. Anthony (Ed.), Evangelical dictionary of Christian education (pp. 253-255). Grand Rapids, MI: Baker.

[23]. Evans, R. I. (1967). Dialogue with Erik Erikson. New York: Harper and Row, Publishers.

[24]. Erikson, E. H.(1963).Childhood and society. New York: W.W. Norton \& Company.

[25]. Daniel, E. A., \& Gresham, C. (1980). Introduction to Christian education. Cincinnati, OH: Standard Publishing.

[26]. Maier, H. W.(1969).Three theories of child development.New York: Harper and Row, Publishers.

[27]. Yount, W. R. (2010). Created to Learn: A Christian teacher's introduction to educational psychology(2nd ed.). Nashville, TN: Broadman and Holman.

[28]. Singer, D. G.,\&Revenson, T. A.(1978).A Piaget Primer: How a child thinks. New York: Plume.

[29]. Shaffer, D. R. (1993). Developmental psychology: Childhood and adolescence (3rd ed.). Belmont, CA: Brooks/Cole Publishing.

[30]. Niebuhr, H. R. (1963). The responsible self: An essay in Christian moral philosophy. San Francisco, CA: Harper and Row, Publishers.

[31]. Dirks, D. (2001). Fowler, James W. III. In M. Anthony (Ed.), Evangelical dictionary of Christian education (pp. 299300). Grand Rapids, MI: Baker.

[32]. Kohlberg, L.(1981).The philosophy of moral development: Essays on moral development volume one.San Francisco, CA: Harper and Row, Publishers.

[33]. Crain, W. (1985). Theories of development concepts and applications. Upper Saddle River, NJ: Prentice-Hall, Inc.

[34]. Clouse, B. (2001). Moral reasoning, the theory of. In M. Anthony (Ed.), Evangelical dictionary of Christian education (pp. 490-491). Grand Rapids, MI: Baker.

[35]. Cully, I. V. (1979). Christian child development.New York, NY: Harper and Row, Publishers.

[36]. Dykstra, C. (1981). Vision and character: A Christian educator's alternative to Kohlberg. Mahwah, NJ: Paulist Press.

[37]. Stokes, K. (1983). Faith development in the adult life cycle. Proceedings of a symposium (St. Paul, Minnesota, August 10-14, 1981). New Haven, CT: Religious Education Association.

[38]. Dell, M. L. (2000). She grows in wisdom, stature, and favour with God: Female development from infancy through menarche. In J. Stevenson-Moessner (Ed.), In her own time (pp. 117-143). Minneapolis, MN: Fortress.

[39]. Fowler, J. W. (1996). Faithful change: The personal and public challenges of postmodern life. Nashville, TN: Abingdon Press.

[40]. Fowler, J. W., \& Dell, M. L. (2005). Stages of faith from infancy through adolescence: Reflections on three decades of faith development theory. In E. C. Roehlkepartain, P. E. King, L. Wagener, \& P. L. Benson (Eds.), The handbook of Spiritual development in childhood and adolescence (pp. 34-45). Thousand Oaks, CA: SAGE Publications.

[41]. Fowler, J. W.(1981).Stages in faith: The psychology of human development and the quest for meaning. San Francisco, CA: Harper and Row, Pub1ishers.

[42]. Dykstra, C., \& Parks, S. (Eds.) (1986a). Faith development and Fowler. Birmingham, AL: Religious Education Press.

[43]. Fowler, W.(1978). Daycare and its effects on early development. Toronto: Ontario Institute for the study of Education.

[44]. Groome, T. H.(1980). Christian Religious education: Sharing our stories and vision.San Francisco, CA: Harper and Row, Publishers. 